\title{
The incidence and impact of cardiac conduction disturbances after transcatheter aortic valve replacement
}

\author{
Shmuel Chen, Katherine H. Chau, Tamim M. Nazif \\ Columbia University Irving Medical Center/New York-Presbyterian Hospital, New York, NY, USA \\ Correspondence to: Tamim M. Nazif, MD. Columbia University Irving Medical Center/New York-Presbyterian Hospital, 177 Fort Washington \\ Avenue, $5^{\text {th }}$ Floor, Room 5C-501, New York, NY 10032, USA. Email: Tmn31@columbia.edu.
}

\begin{abstract}
Transcatheter aortic valve replacement (TAVR) has developed into an established therapy for patients with severe aortic stenosis (AS) across the spectrum of surgical risk. Despite improvements in transcatheter heart valve (THV) technologies and procedural techniques, cardiac conduction disturbances, including high degree atrioventricular block (AVB) requiring permanent pacemaker (PPM) implantation and new-onset left bundle branch block (LBBB), remain frequent complications. TAVR-related conduction disturbances occur due to injury to the conduction system from interactions with interventional equipment and the transcatheter valve stent frame. Risk factors for post-TAVR conduction disturbances have been identified and include clinical characteristics, baseline electrocardiogram findings (right bundle branch block), anatomic factors, and potentially modifiable procedural factors (type of transcatheter valve, depth of implantation, over-sizing). New-onset LBBB and PPM implantation after TAVR have been shown to be associated with adverse longterm clinical outcomes, including mortality and heart failure hospitalization. These clinical consequences are likely to be of increasing importance as TAVR is utilized in younger and lower risk population. This review provides an updated overview of the literature regarding the incidence, predictors, and clinical outcomes of TAVR-related conduction disturbances, as well as proposed strategies for the management of this frequent clinical challenge.
\end{abstract}

Keywords: Transcatheter aortic valve replacement (TAVR); TAVI; left bundle branch block (LBBB); pacemaker; conduction

Submitted Sep 10, 2020. Accepted for publication Oct 21, 2020.

doi: 10.21037/acs-2020-av-23

View this article at: http://dx.doi.org/10.21037/acs-2020-av-23

\section{Introduction}

As transcatheter aortic valve replacement (TAVR) has matured into an established therapy for patients with severe aortic stenosis (AS) across the spectrum of surgical risk, the rates of most procedural complications have decreased with improvements in technology and procedural techniques (1-4). However, cardiac conduction disturbances remain a frequent complication of TAVR, ranging from relatively benign intraventricular conduction delay to more significant left bundle branch block (LBBB) and high degree or complete atrioventricular block (AVB) requiring permanent pacemaker (PPM) implantation. The occurrence of conduction disturbances during TAVR is due to a complex interplay of patient, device and procedural factors. The prevention and management of these conduction abnormalities remains an important clinical challenge in contemporary practice. In this article, we review the current state of knowledge regarding the incidence and clinical implications of conduction disturbances after TAVR and explore related patient management strategies.

\section{Anatomic relationships and mechanisms of conduction disturbances}

The atrioventricular (AV) conduction system arises from the atrioventricular node (AVN), which lies in the superficial paraseptal endocardium of the inferior right atrium within 


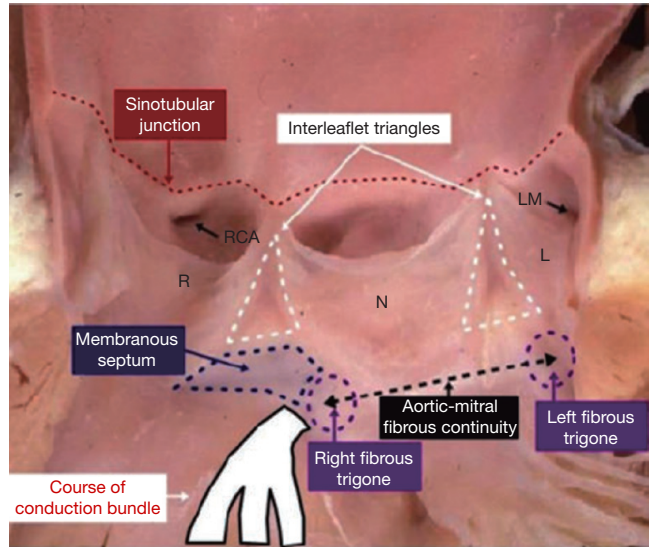

Figure 1 Anatomic relationship of the aortic valve with the cardiac conduction system. The aortic root opened from the left ventricle is shown. The conduction bundle exits below the base of the interleaflet triangle separating the noncoronary and right coronary leaflets. L, left coronary leaflet; LM, left main coronary artery; N, noncoronary leaflet; R, right coronary leaflet; RCA, right coronary artery. Reprinted with permission from Ferreira et al. 2010 (6).

the triangle of Koch (5). From here, the penetrating bundle of His enters the central fibrous body and traverses beneath the membranous septum before crossing to the left side of the heart. The branching bundle emerges on the crest of the muscular ventricular septum and gives rise to the left bundle branch and its fascicles. In this location, the His bundle and proximal left bundle branch are closely related to the base of the inter-leaflet triangle between the non-coronary and the right coronary leaflets of the aortic valve (Figure 1) (7). The anatomic proximity of this portion of the conduction system to the distal landing zone of the transcatheter heart valve (THV) in the left ventricular outflow tract (LVOT) renders it vulnerable to injury during TAVR. Importantly, interindividual variability in the anteroposterior relationship of the AVN to the apex of the triangle of Koch and the length and depth of the His bundle and proximal left bundle may modulate patient susceptibility to conduction system damage (8).

TAVR-related conduction disturbances, including high degree AVB and LBBB, have been shown to occur due to direct or indirect injury to the conducting tissues from interactions with interventional equipment and the THV stent frame $(8,9)$. Elegant pathological studies have demonstrated several specific mechanisms of TAVR-related conduction system injury, including direct compression, hematoma and ischemia. For example, one autopsy study of a patient who developed complete AVB after TAVR showed localized hematoma within the ventricular septum at the site of prosthesis expansion, and microscopic examination revealed compression of the bundle of His by the hematoma (10). Another pathological study of a patient who developed persistent AVB requiring PPM after TAVR, who then died of unrelated causes, showed both macroscopic and microscopic evidence of ischemic injury of the basal left septum involving the conducting tissues just apical to the THV. Studies have shown that conduction abnormalities typically develop during the TAVR procedure, in descending order of frequency, during balloon pre-dilation, THV expansion, THV positioning, balloon catheter positioning, and wire-crossing of the aortic valve (11). Less commonly, conduction disturbances may occur in a delayed fashion after the conclusion of the TAVR procedure $(12,13)$.

\section{High burden of underlying conduction system disease}

The high frequency of conduction disturbances following TAVR may also be related to the high prevalence of baseline conduction abnormalities in patients with severe AS requiring treatment. It is likely that underlying degenerative conduction system disease increases the susceptibility of the conduction system to injury during TAVR. The prevalence of conduction abnormalities varies widely in different populations and is related to age and medical comorbidities, including cardiovascular disease. LBBB is relatively uncommon in healthy individuals $(1.4 \%$ at age $67,2.3 \%$ at age 75 , and $5.7 \%$ at age 80 ), but occurs in up to $25 \%$ of patients with chronic heart failure (14). Among patients with AS, the prevalence of ventricular conduction abnormalities increases with AS severity, with a reported frequency of LBBB in $2.1 \%, 4.6 \%$ and $8.1 \%$ of patients with mild, moderate and severe AS, respectively (15). In patients undergoing TAVR, the prevalence of preexisting LBBB ranges from $2 \%$ to $24 \%$ (16). The frequency of pre-existing PPM also varies widely and appears to be correlated with patient age, comorbidities and surgical risk. In the PARTNER 1 and CoreValve US Pivotal trials that enrolled patients with high or prohibitive surgical risk, the prevalence of pre-existing PPM was $21 \%$ to $22 \%(2,4,17)$. In contrast, in the PARTNER 3 and Evolut Low Risk trials, which enrolled younger patients with fewer comorbidities, the prevalence of PPM at baseline was between $2 \%$ and $3.4 \%(18,19)$. 
The high frequency of preexisting PPM and LBBB in patients undergoing TAVR is also important to bear in mind during analysis and discussion of new conduction disturbances after TAVR. Unfortunately, many of the existing TAVR studies have reported the incidence of new PPM as a proportion of the entire study population, which includes patients with preexisting PPM who are not at risk for the outcome. This issue complicates comparisons of new conduction disturbances across studies due to baseline differences in study populations, but has recently improved with increasing recognition of this problem. It is therefore recommended that future authors exclude patients with preexisting PPM from the calculation of new PPM rates after TAVR and that this convention also be adopted for other conduction disturbances.

\section{PPM implantation after TAVR}

High degree or complete AVB and other bradyarrhythmias requiring $\mathrm{PPM}$ implantation occur in an estimated $3 \%$ to $7 \%$ of patients undergoing isolated surgical aortic valve replacement (SAVR) for AS $(2,20)$. Early in the TAVR experience, it was recognized that the rate of PPM implantation was higher on average with TAVR than SAVR, but with significant variability based on the THV system used. Meta-analysis including more than 11,000 patients treated with early generation THV platforms showed average new PPM rates of $13 \%$ to $17 \%(16,21)$. The requirement for PPM was lower $(6 \%)$ with the balloonexpandable SAPIEN (ESV) (Edwards Lifesciences, Irvine, CA, USA) THV and substantially higher (25-28\%) with the self-expanding CoreValve (MCV) (Medtronic, Minneapolis, MN, USA) THV. The first generation mechanicallyexpandable Lotus valve (Boston Scientific, Marlborough, MA, USA) was associated with an even higher new PPM rate (greater than $30 \%)(22,23)$. The high degree of variability in PPM requirement across THV platforms has been attributed to differences in the mechanism of expansion, stent frame properties, radial forces and depth of implantation below the aortic valve annulus.

Recent evidence suggests that new PPM rates after TAVR have evolved along with newer generation THV systems and contemporary procedural techniques (Table 1). Several early studies with the newer generation balloonexpandable Sapien $3 \mathrm{THV}$ actually showed an increase in the new PPM rate to $10 \%$ to $13 \%(24,56,57)$. However, subsequent analyses suggested that this may have been due to a learning curve related to differences in THV deployment and depth of implantation $(27,58,59)$. More recently, several contemporary studies with the SAPIEN 3 and SAPIEN 3 Ultra valves have demonstrated new PPM rates as low as $4.4 \%$ to $6.5 \%$, similar to the early generation balloon-expandable valves $(18,34,35)$. Recent studies have also shown a reduction in the rate of new PPM with the self-expanding Evolut R and PRO valves (Medtronic, Minneapolis, MN, USA) to between $12 \%$ and $20 \%(19,42,60)$. Smaller series have suggested that it may be possible to reduce PPM after TAVR with self-expanding valves even further (less than $10 \%$ ) with expert operators and careful attention to best procedural practices $(43,61)$. Similarly, early results with the newer mechanicallyexpandable Lotus with Depth Guard and Lotus Edge THVs have demonstrated lower PPM rates of approximately $15 \%$ to $20 \%(23,55,62)$. Several other newer generation THVs have also been associated with relatively low rates of new PPM, including approximately $10 \%$ with the Acurate Neo valve (Boston Scientific, Marlborough, MA, USA) and 15\% with Portico with FlexNav system (Abbott Vascular, Abbott Park, IL, USA) $(31,44,54)$. As TAVR continues to expand into younger and lower risk patient populations, further reduction of PPM rates to near those achieved with SAVR will likely remain an important goal.

\section{PPM indication and timing}

The most common indication for PPM implantation after TAVR is high degree or complete AVB, which is responsible for $60 \%$ to $80 \%$ of cases, followed by first-degree AVB with bundle branch block and sick sinus syndrome (63-66). The vast majority of TAVR-related conduction disturbances ( $>90 \%)$ occur within the first week after the procedure and during the index hospitalization, and the median day of PPM implantation is day $3(63-65,67)$. "Delayed" high degree AVB after the immediate post-procedure period may occur in up to $7 \%$ of patients but has been shown to be extremely rare in patients with a normal electrocardiogram (EKG) [absence of preexisting right bundle branch block (RBBB), new LBBB, and first-degree AVB] (68). In addition to EKG, findings of both pre-existing RBBB and prolonged $\mathrm{HV}$ interval by invasive electrophysiology study have also been independently associated with mortality after TAVR, presumably due to the risk of progression of complete AVB (69-71).

Among patients with new PPM after TAVR, studies have shown that only $40 \%$ to $70 \%$ are pacemaker-dependent at 1 year, regardless of the THV implanted $(22,63)$. A large 


\begin{tabular}{|c|c|c|c|c|c|}
\hline \multirow{8}{*}{ SAPIEN 3} & Kodali et al., 2016, (24) & 583 & High & N/A & 13.3 \\
\hline & Abramowitz et al., 2016, (25) & 245 & All-comers & N/A & 14.3 \\
\hline & De Torres-Alba et al., 2016, (27) & 162 & All-comers & 13 & $\mathrm{~N} / \mathrm{A}$ \\
\hline & Wendler et al., 2017, (28) & 1,947 & All-comers & N/A & 12.0 \\
\hline & Gonska et al., 2017, (29) & 335 & All-comers & $23.5^{\mathrm{c}}$ & $18.4^{\mathrm{c}}$ \\
\hline & Nazif et al., 2019, (32) & 589 & Intermediate & $20.7^{c}$ & $\mathrm{~N} / \mathrm{A}$ \\
\hline & Deharo et al., 2020, (33) & 10,459 & All-comers & N/A & 20.5 \\
\hline & Nazif et al., 2020, (34) & 1,324 & All-comers & N/A & $6.2^{b, c}$ \\
\hline \multirow[t]{2}{*}{ SAPIEN 3 UItra } & \multirow[t]{2}{*}{ Saia et al., 2020, (35) } & 139 & All-comers & N/A & $4.4^{\mathrm{c}}$ \\
\hline & & 1,324 & All-comers & N/A & $6.4^{\mathrm{b}, \mathrm{c}}$ \\
\hline \multirow{7}{*}{ Evolut R } & Reardon et al., 2017, (39) & 864 & Intermediate & N/A & 25.9 \\
\hline & Noble et al., 2017, (40) & 317 & All-comers & N/A & 22.1 \\
\hline & Popma et al., 2019 ${ }^{a}$, (19) & 1,468 & Low & N/A & 17.4 \\
\hline & Finkelstein et al., 2019, (30) & 512 & All-comers & 28.6 & $17.5^{\mathrm{b}}$ \\
\hline & Deharo et al., 2020, (33) & 10,459 & All-comers & $\mathrm{N} / \mathrm{A}$ & 25.9 \\
\hline & Zaid et al., 2020, (41) & 194 & All-comers & 20.6 & $\mathrm{~N} / \mathrm{A}$ \\
\hline & Forrest et al., 2020, (42) & 11,295 & All-comers & N/A & $19.6^{c}$ \\
\hline
\end{tabular}

Table 1 (continued) 


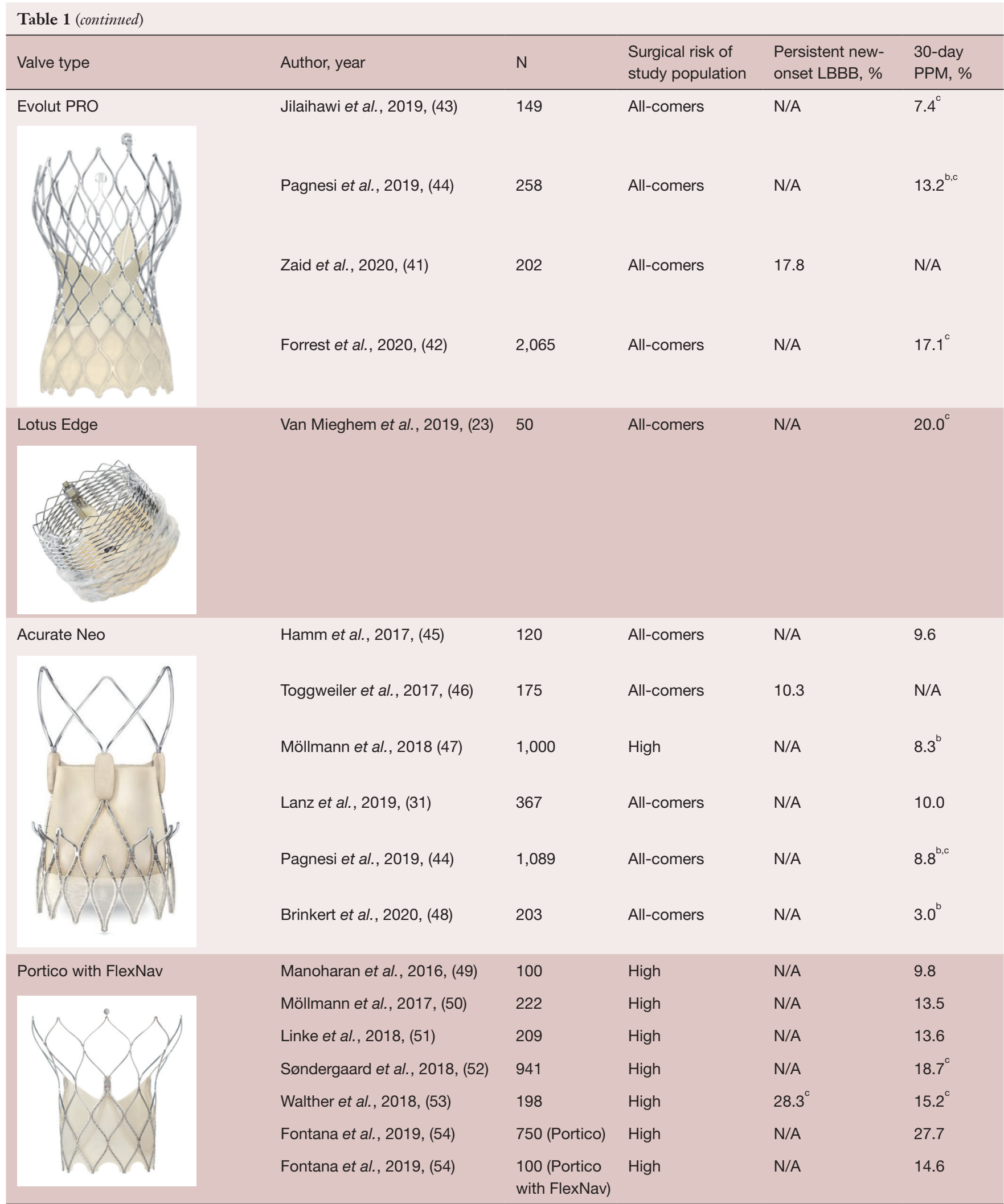

Table 1 (continued) 


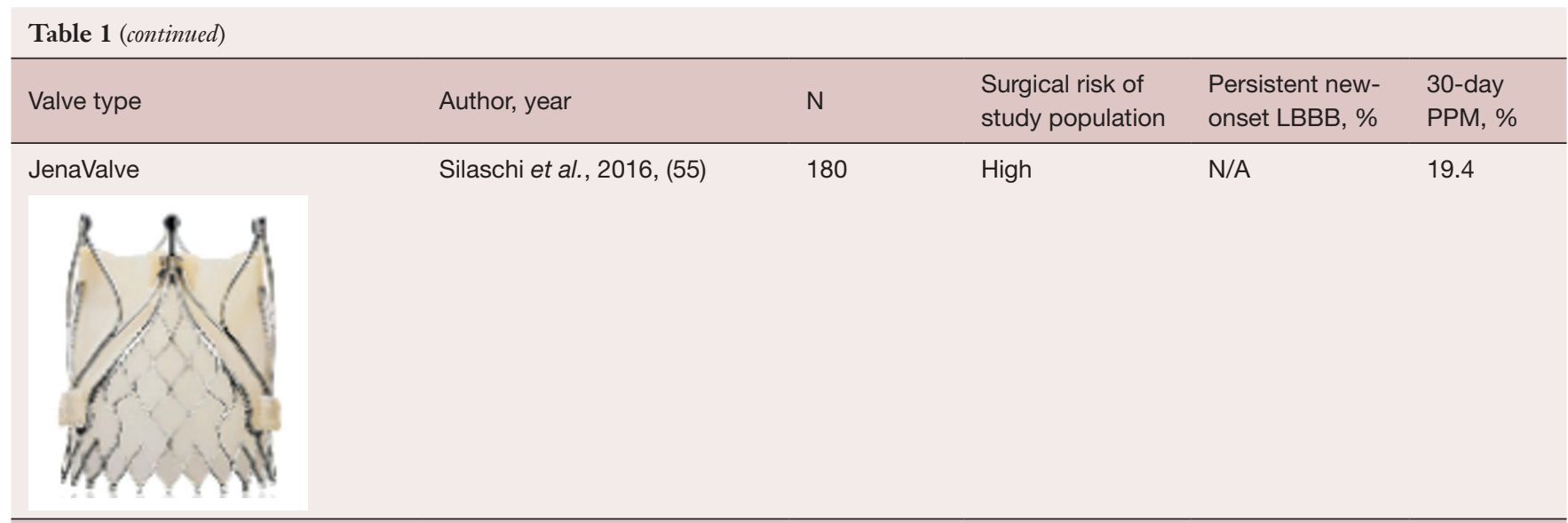

Representative studies were restricted to those published after 2016 and with sample size $\geq 100$ (unless only smaller were available). KMestimated event rates of 30-day PPM were presented when possible. ${ }^{a}$, rates of PPM reported in this study were not separated by valve type; ${ }^{b}$, reported rate is the proportion of patients with new PPM (not KM estimated); ${ }^{c}$, patients with PPM or LBBB at baseline (depending on the outcome of interest) were excluded. LBBB, left bundle branch block; PPM, permanent pacemaker; THV, transcatheter heart valve.

study of patients who underwent TAVR with a balloonexpandable valve found that the proportion of patients with new PPM who had ventricular pacing on EKG was only $47 \%$ at discharge $/ 7$ days, $51 \%$ at 30 days, $47 \%$ at 6 months and $50.5 \%$ at one year. Thus, recovery of the conduction system to the point that the patient does not require continuous pacing occurs in approximately $50 \%$ of PPM recipients and in the majority of cases, occurs within the first month after valve implantation (63). Other studies have also suggested that only approximately half of patients who receive PPM after TAVR with self-expanding and mechanically-expandable valves were pacemaker dependent by 1 month (22). Although the appropriate level of pacemaker dependency after TAVR has not been defined (even small percentages of pacing could be lifesaving if for complete AVB), this may argue for a more conservative approach to PPM implantation during the post-TAVR period as a means to decrease new PPM rates in appropriate patients. Predictors of long-term PPM-dependency that may also be useful in this regard include high grade AVB after TAVR, baseline RBBB, female sex, and depth of implantation (22).

\section{Predictors of PPM}

Substantial research has focused on the identification of predictors of cardiac conduction disturbances after TAVR. These risk factors can be broadly categorized as clinical, electrocardiographic, anatomic, or procedural in nature (Figure 2). Several of the earliest recognized and most reproducible risk factors for new PPM after TAVR have included preexisting RBBB, use of a self-expanding THV, and depth of implantation below the aortic annulus plane (13). An influential meta-analysis from 2014 confirmed RBBB [risk ratio (RR), 2.89; $\mathrm{P}<0.01$ ] and the use of a selfexpanding valve $(\mathrm{RR}, 2.54 ; \mathrm{P}<0.01)$ as potent risk factors for PPM, and also identified male sex, first-degree AVB, and left anterior hemiblock as predictors (16). Also in 2014, an analysis of almost 2,000 patients from the PARTNER trial integrated additional echocardiographic variables and identified prosthesis diameter over-sizing relative to the LVOT and left ventricle end-diastolic diameter, in addition to RBBB, as risk factors for PPM (63). Multiple additional studies have now confirmed THV depth of implantation as the most important modifiable procedural predictor of PPM across different THV platforms $(23,27,58,72)$.

With the widespread adoption of cardiac computed tomography (CT) imaging with three-dimensional reconstruction of the aortic valve complex for TAVR procedural planning, studies have increasingly focused on anatomic risk factors for conduction disturbances. Important new predictors of PPM after TAVR have included THV over-sizing relative to the annulus or LVOT area, calcium location and burden, and membranous septum length (MSL), a surrogate for the depth below the aortic valve annulus at which the conduction system crosses to 


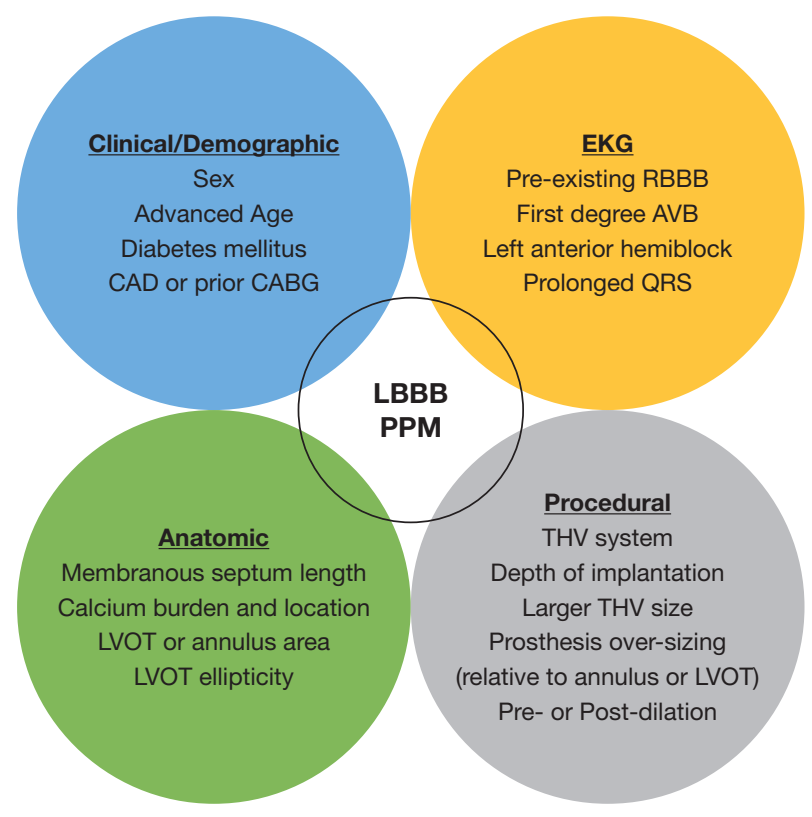

Figure 2 Predictors of PPM implantation and new-onset LBBB after TAVR. Risk factors for new PPM and LBBB after TAVR can be divided into broad categories, including clinical or demographic, EKG, Anatomic and Procedural. The list is not intended to be exhaustive and not all risk factors apply to both PPM and LBBB. $\mathrm{AVB}$, atrioventricular block; CABG, coronary artery bypass graft; CAD, coronary artery disease; EKG, electrocardiogram; LBBB, left bundle branch block; LVOT, left ventricular outflow tract; PPM, permanent pacemaker; RBBB, right bundle branch block; TAVR, transcatheter aortic valve replacement; THV, transcatheter heart valve.

the left side of the heart $(73,74)$. For example, one CTbased study found that the volume of calcium in the left coronary cusp and RBBB were independent predictors of PPM, while another identified the volume of calcium in the LVOT below the left and right coronary cusps and depth of implantation as independent predictors $(58,74,75)$. Another recent CT study identified calcium volume below the noncoronary cusp and short MSL as predictors of PPM with the balloon-expandable THV and combined these with RBBB to create a risk score for PPM after TAVR $(58,74)$. Jilaihawi et al. subsequently confirmed that implantation depth greater than MSL was independently associated with new PPM with a self-expanding THV and demonstrated the potential utility of an implantation technique based on MSL in reducing PPM (43). Continued research in this area should facilitate ongoing efforts to reduce new PPM during TAVR to the extent possible.

\section{Prognostic implications of PPM}

The long-term clinical impact of PPM implantation after TAVR remains controversial. On the one hand, PPM exerts an obvious protective effect with respect to AVB and potentially life-threatening bradyarrhythmias. On the other hand, chronic right ventricular pacing has been shown to result in ventricular dyssynchrony, which may lead to adverse left ventricular remodeling and reduced ejection fraction (76). Several randomized trials in other patient populations have demonstrated deleterious effects of chronic right ventricular pacing, including increased risk of atrial fibrillation, ventricular arrhythmia and heart failure (77-79). In the TAVR population, new PPM has also been associated with a reduction in LV stroke volume and poorer recovery of left ventricular systolic dysfunction at six months to 1 year $(64,80)$.

A recent, large meta-analysis, including more than 22,000 TAVR patients demonstrated that new PPM was associated with a modest, but statistically significant increase in 1 year all-cause mortality $(\mathrm{RR}, 1.09 ; \mathrm{P}=0.04)$ but not cardiac mortality (RR, 0.84; $\mathrm{P}=0.13)$. New $\mathrm{PPM}$ was also associated with an increase in heart failure hospitalization at 1 year $(\mathrm{RR}, 1.18 ; \mathrm{P}=0.02)$. These findings echo those of the MOST and DAVID trials, which first showed an increased risk of heart failure hospitalization with chronic RV pacing in patients with PPM $(78,79)$. It is also likely based on experience with other populations of patients with PPM that there will be additional long-term adverse consequences to PPM after TAVR, such as lead dysfunction, need for generator replacement, infection and tricuspid valve regurgitation. Future long-term studies will be needed to identify these late complications of PPM after TAVR, which are likely to become increasingly relevant as TAVR is utilized in younger, lower risk populations.

\section{Economic implications}

In the current era of increased focus on resource utilization, it is also important to consider the fact that TAVR-related PPM is an important driver of peri-procedural costs. Studies have shown that PPM implantation after TAVR is associated with longer duration of both intensive care unit and overall hospital stay $(81,82)$. Several recent analyses have also shown the negative impact of new PPM on the cost effectiveness of TAVR $(83,84)$. The costs associated with PPM are likely to further increase over time in younger patients who may require future PPM-related interventions. 


\section{New-onset LBBB after TAVR}

\section{Incidence}

New LBBB is relatively infrequent following SAVR for isolated AS with reported rates of only $4 \%$ to $8 \%(18,85)$. However, new-onset LBBB occurs much more frequently after TAVR, with reported rates ranging from $4 \%$ to $60 \%$ in the first generation THV systems (73). Similar to PPM, the incidence of new LBBB varies with the THV platform used and was lower in the early-generation, balloon-expandable SAPIEN valves $(\sim 10 \%$ to $25 \%)$ than the self-expanding CoreValve $(\sim 20 \%$ to $50 \%)(7,32,73,85,86)$. The incidence of new LBBB with the first-generation, mechanicallyexpandable Lotus valve was even higher, ranging from $50 \%$ to over $75 \%(87,88)$. As with other conduction disturbances, the high variability in the rate of new-onset LBBB across THV platforms is likely attributable to differences in mechanism of expansion, radial forces exerted by the stent frame, and depth in the LVOT (89).

As with PPM, the incidence of new-onset LBBB has continued to evolve with changes in THV devices and procedural techniques (Table 1). In several early studies, a higher rate of new $\mathrm{LBBB}$ was reported with the newer generation SAPIEN 3 valve compared with SAPIEN XT, for example $20.7 \%$ vs. $9.7 \%$ in the PARTNER II experience $(32,90)$. As with PPM, this increase may have been due in part to changes in depth of implantation, and the reported rates of new LBBB after TAVR with SAPIEN 3 have ranged from approximately $13 \%$ to $24 \%$, similar to prior generation SAPIEN valves $(18,32,73)$. However, the rate of new LBBB with SAPIEN 3 was also higher than expected (24\%) in the recently published PARTNER 3 low-risk trial, warranting further investigation. Interestingly, the newer, self-expanding Evolut R and Evolut R Pro THVs appear to be associated with lower rates of new-LBBB than the earlier generation CoreValve, ranging from $18 \%$ to $28 \%$, although further study is also necessary $(30,41)$. Limited data exist regarding the rates of new $\mathrm{LBBB}$ with other newer generation THV systems.

Several studies have investigated the time course of new LBBB development and potential resolution after TAVR. Detailed analysis of serial EKGs has demonstrated that new LBBB occurs at the time of the procedure in the vast majority of cases and is frequently transient, resolving prior to hospital discharge in more than a third of all cases $(13,91)$. Among patients with persistent LBBB, it appears to resolve in another $40 \%$ by 30 days, after which the rate of LBBB remains stable through 1 year $(12,32,92,93)$. Thus, newonset LBBB that persists until 30 days appears to become chronic. Late-onset (post-discharge) LBBB is uncommon, occurring in only $2 \%$ to $2.5 \%$ of patients at 30 days and 1 year $(12,32)$.

\section{Predictors of new LBBB}

The occurrence of new-onset LBBB after TAVR is attributable to injury to the left bundle branch at the immediate exit of the bundle of His beneath the membranous septum, as indicated by the typical pure pattern of $\mathrm{LBBB}$ on the EKG (89). It is not surprising that the predictors of new LBBB after TAVR closely mirror those of AVB and PPM. Among the earliest and most consistently identified independent predictors of LBBB are the type of THV (self-expanding) and depth of implantation $(13,73,92,94,95)$. Additional clinical and EKG predictors that have been identified in various studies include female sex, diabetes mellitus, previous coronary artery bypass grafting and pre-procedural conduction disturbances (mainly prolonged QRS) $(13,73,96,97)$. More recent CT-based analyses have also demonstrated the importance of anatomic risk factors, including short MSL, LVOT ellipticity and calcium burden and location $(41,98)$. Finally, studies have highlighted important and potentially modifiable procedural risk factors including depth of implantation relative to the MSL, larger THV size, THV over-sizing (relative to annulus or LVOT) and balloon postdilation $(13,41,73,94)$.

\section{Clinical impact of new LBBB}

The prognostic importance of new-onset, persistent LBBB after TAVR has been the subject of extensive debate. Several early observational studies identified an association of new LBBB with increased long-term (>1 year) all-cause and cardiovascular mortality $(12,73,96,97)$, while other studies failed to detect such an association (13,81,91,92,99-101). The disparate results of these initial studies may have been due to differences in the definitions of LBBB, inadequate duration of follow-up, and the inclusion of primarily high risk patients with high overall mortality and multiple competing risk factors. However, as the field has matured, it has become increasingly clear that new LBBB after TAVR is associated with adverse long-term outcomes, including mortality. Recently, a large meta-analysis including almost 
8,000 patients demonstrated that new LBBB was associated with an increased risk of both all-cause $(\mathrm{RR}, 1.32 ; \mathrm{P}<0.001)$ and cardiac mortality ( $\mathrm{RR}, 1.46 ; \mathrm{P}<0.001)$, as well as heart failure hospitalization ( $R R, 1.35 ; \mathrm{P}=0.02$ ) at 1 year followup (81). Concerningly, a recent large analysis from the PARTNER 2 trial that included intermediate risk patients with 2 years follow-up also showed new LBBB after TAVR to be a significant independent predictor of both all-cause [hazard ratio (HR), 1.98; $\mathrm{P}<0.001$ ] and cardiovascular $(\mathrm{HR}$, 2.66; $\mathrm{P}<0.001$ ) mortality (32). New-onset LBBB is therefore likely to remain a matter of increasing concern as TAVR expands to younger and lower-risk patients with fewer additional risks and longer expected survival.

Beyond mortality, new-onset LBBB after TAVR has been shown to be associated with increased duration of the index hospitalization and higher rates of repeat hospitalization at 1 year and beyond following TAVR $(32,92)$. New LBBB has also been consistently associated with higher requirement for PPM both at 30 days and at long-term follow-up $(32,73,92,101)$. Concerningly, the prospective, multicenter MARE study, which employed implantable cardiac monitors in 103 patients with persistent new-onset LBBB postTAVR, demonstrated significant bradyarrhythmic events in $20 \%$ of patients, of which $76 \%$ of events were clinically silent (93). These data raise the question of whether more intensive, long-term monitoring may be justified in patients with new LBBB or other significant conduction disturbances after TAVR.

The specific mechanisms by which new LBBB after TAVR increases mortality among patients with new-onset LBBB after TAVR remains unclear. The most obvious potential cause is progression of the conduction disturbance to a life-threatening bradyarrhythmia, including highdegree or complete AV block. Indeed, one analysis of late cardiac mortality after TAVR showed that new-LBBB, particularly with QRS width greater than 160 milliseconds, was an independent predictor of sudden cardiac death. However, in the MARE study of 103 patients with new LBBB, there was only a single episode of sudden death, which occurred in a patient without any recorded bradyarrhythmia. Another potential mechanism for increased mortality is progression of heart failure, and multiple studies have shown ventricular dyssynchrony and worsened recovery of left ventricular systolic function in patients with new LBBB after $\operatorname{TAVR}(13,32,82,92,100)$. Intraventricular dyssynchrony has also been shown to be an important factor in ventricular arrhythmogenesis and improved synchrony is associated with a reduction in ventricular arrhythmic events (102). LBBB has also been shown to have an impact on diastolic function in patients with dilated cardiomyopathy, and diastolic dysfunction has been described in patients with new-LBBB post-TAVR $(103,104)$. The complex interplay between these possible mechanisms for adverse outcomes in patients with new LBBB complicates therapeutic decision making and must be an important focus for ongoing research.

\section{Management of TAVR-related conduction disturbances}

The above-described predictors of cardiac conduction disturbances may assist in identifying at-risk patients prior the TAVR procedure. During the TAVR procedure, particular attention should be paid to potentially modifiable risk factors, including THV selection, THV sizing in borderline zones, depth of implantation, and balloon preand post-dilation. As clinicians gain comfort with the measurement of novel CT predictors, particularly MSL and calcium distribution, these may further guide procedural strategies. Patient-specific risk assessment for conduction disturbances may also assist in subsequent post-procedural management, for example by helping to determine the need for maintenance of a temporary transvenous pacemaker and patient candidacy for early hospital discharge.

The management of TAVR-related conduction disturbances during the post-procedural period remains controversial and highly variable across sites. For example, the WoRldwIde TAVI ExperieNce (WRITTEN) survey included 250 centers from 38 different countries and found substantial variability in the use of post-procedural EKG monitoring, temporary pacemakers and PPM implantation (105). Important remaining questions include the optimal indications and timing for PPM after TAVR, management of new LBBB, and duration and type of monitoring for patients with other conduction disturbances. The need for an improved understanding of PPM indications after TAVR is highlighted by the growing body of literature suggesting that a significant proportion of patients who receive PPM after TAVR are not pacemaker dependent at follow-up $(22,63,106)$. The rate of ventricular pacing is likely even lower $(<1 \%)$ among patients who receive $P$ PM for new-onset $\mathrm{LBBB}$ alone $(100,101)$. The appropriate use of other strategies, such as extended inpatient or outpatient rhythm monitoring, temporary 


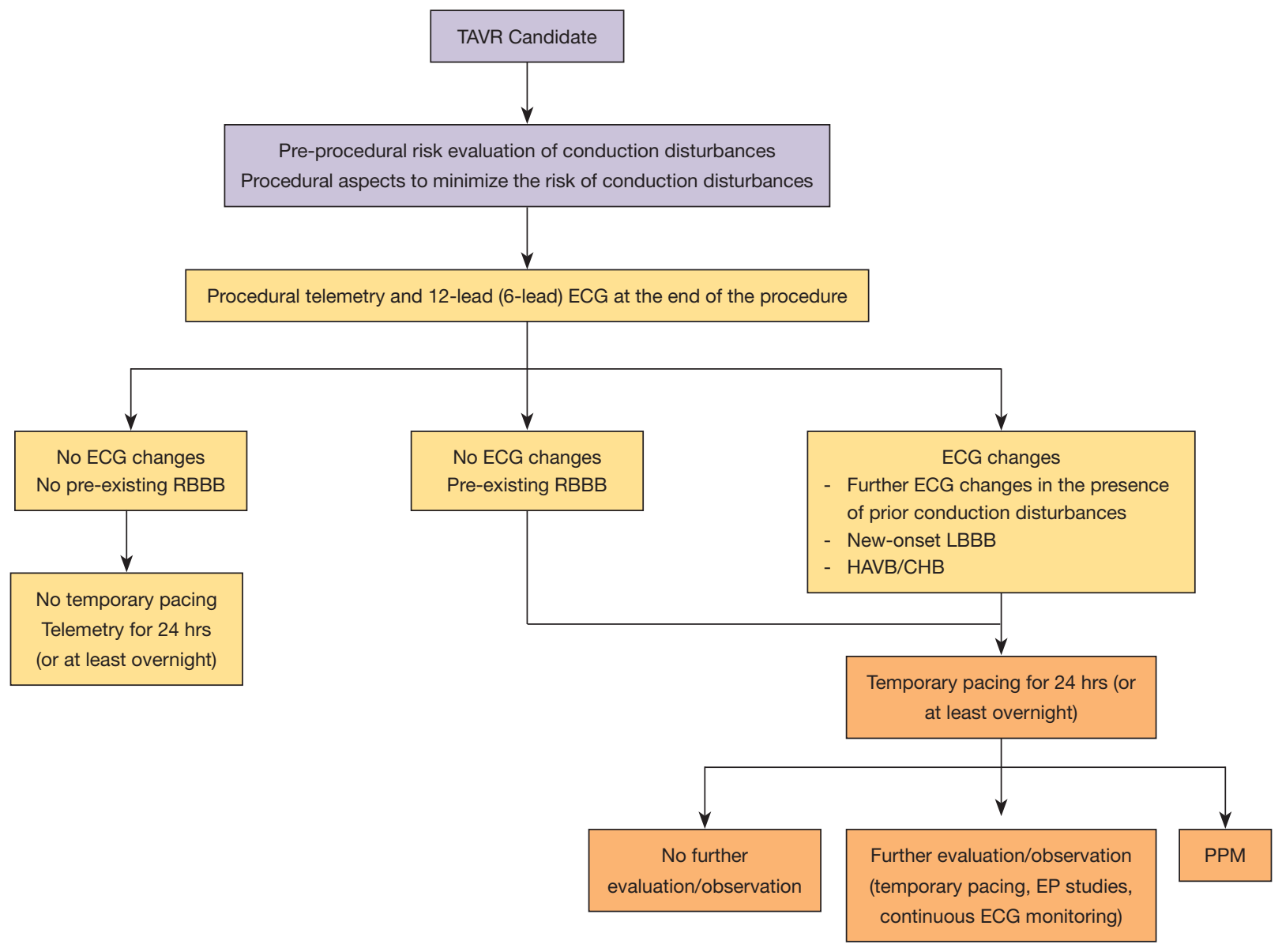

${ }^{*}$ Consider earlier discontinuation of temporary pacing if regression of ECG changes in <24 $\mathrm{h}$ (except for pre-existing RBBB).

Figure 3 Expert panel algorithm for the management of conduction disturbances after TAVR. Algorithm on how best to manage conduction disturbances that develop after TAVR. ECG, electrocardiogram; EP, electrophysiology; LBBB, left bundle branch block; PPM, permanent pacemaker; RBBB, right bundle branch block; TAVR, transcatheter aortic valve replacement. Reprinted with permission from Rodés-Cabau et al. 2019 (107).

pacing or electrophysiological study in at-risk patients, such as those with new LBBB or pre-existing RBBB, also remains unclear.

Recent efforts to address the inconsistencies in the management of conduction disturbances include the publication of various patient management algorithms (107). For example, a Fournal of the American College of Cardiology (JACC) Scientific Expert Panel publication divided patients with TAVR-related conduction disturbances into five groups based on baseline and post-procedure EKG abnormalities, and proposed practical management strategies for each group (107). These groups included: no EKG changes in patients without RBBB pre-TAVR, no EKG changes in patients with pre-existing RBBB, EKG changes in patients with pre-existing $\mathrm{RBBB}$ or other conduction abnormalities, new-onset $\mathrm{LBBB}$, and high-degree AVB during the procedure. Based on the risk of bradyarrhythmia requiring pacemaker in each group, the algorithm provides guidance regarding the duration of temporary pacing, telemetry monitoring, and hospital discharge and consideration of the need for PPM, electrophysiologic study, or outpatient rhythm monitoring (Figure 3). Further study is required to prospectively validate each of these management strategies for TAVR-related conduction disturbances. In the interim, a conservative approach can be recommended with enhanced monitoring of TAVR recipients with conduction 
disturbances or risk factors for their development and adoption of guideline-based recommendations for PPM implantation.

\section{Conclusions}

TAVR is being increasingly utilized in the treatment of patients with severe symptomatic AS across the spectrum of surgical risk. Despite significant improvement in device technologies and implantation techniques, cardiac conduction disturbances, including new PPM and LBBB, remain a frequent complication of the procedure. Recent research has identified predictors of these conduction disturbances that may assist in identifying at-risk patients. The most recent evidence suggests a significant adverse clinical impact of new LBBB after TAVR, while the impact of PPM remains less clear, and further long-term studies are required. The optimal management strategies for TAVRrelated conduction disturbances remain controversial, and an individualized approach is recommended while awaiting further research.

\section{Acknowledgments}

Funding: None.

\section{Footnote}

Conflicts of Interest: TMN discloses receiving consulting fees or honoraria from Edwards LifeSciences, Medtronic, Boston Scientific, BioTrace Medical, and consulting and equity for Venus Medtech. The other authors have no conflicts of interest to disclose.

Open Access Statement: This is an Open Access article distributed in accordance with the Creative Commons Attribution-NonCommercial-NoDerivs 4.0 International License (CC BY-NC-ND 4.0), which permits the noncommercial replication and distribution of the article with the strict proviso that no changes or edits are made and the original work is properly cited (including links to both the formal publication through the relevant DOI and the license). See: https://creativecommons.org/licenses/by-nc-nd/4.0/.

\section{References}

1. Makkar RR, Fontana GP, Jilaihawi H, et al. Transcatheter aortic-valve replacement for inoperable severe aortic stenosis. N Engl J Med 2012;366:1696-704.

2. Smith CR, Leon MB, Mack MJ, et al. Transcatheter versus surgical aortic-valve replacement in high-risk patients. $\mathrm{N}$ Engl J Med 2011;364:2187-98.

3. Leon MB, Smith CR, Mack MJ, et al. Transcatheter or surgical aortic-valve replacement in intermediate-risk patients. N Engl J Med 2016;374:1609-20.

4. Adams DH, Popma JJ, Reardon MJ, et al. Transcatheter aortic-valve replacement with a self-expanding prosthesis. N Engl J Med 2014;370:1790-8.

5. Piazza N, de Jaegere P, Schultz C, et al. Anatomy of the aortic valvar complex and its implications for transcatheter implantation of the aortic valve. Circ Cardiovasc Interv 2008;1:74-81.

6. Ferreira ND, Caeiro D, Adão L, et al. Incidence and predictors of permanent pacemaker requirement after transcatheter aortic valve implantation with a selfexpanding bioprosthesis. Pacing Clin Electrophysiol 2010;33:1364-72.

7. van der Boon RM, Nuis RJ, Van Mieghem NM, et al. New conduction abnormalities after TAVI--frequency and causes. Nat Rev Cardiol 2012;9:454-63.

8. Young Lee M, Chilakamarri Yeshwant S, Chava S, et al. Mechanisms of heart block after transcatheter aortic valve replacement - cardiac anatomy, clinical predictors and mechanical factors that contribute to permanent pacemaker implantation. Arrhythm Electrophysiol Rev 2015;4:81-5.

9. Hamdan A, Guetta V, Klempfner R, et al. Inverse relationship between membranous septal length and the risk of atrioventricular block in patients undergoing transcatheter aortic valve implantation. JACC Cardiovasc Interv 2015;8:1218-28.

10. Moreno R, Dobarro D, Lopez de Sa E, et al. Cause of complete atrioventricular block after percutaneous aortic valve implantation: insights from a necropsy study. Circulation 2009;120:e29-30.

11. Nuis RJ, Van Mieghem NM, Schultz CJ, et al. Timing and potential mechanisms of new conduction abnormalities during the implantation of the Medtronic CoreValve System in patients with aortic stenosis. Eur Heart J 2011;32:2067-74.

12. Houthuizen $\mathrm{P}$, van der Boon RM, Urena M, et al. Occurrence, fate and consequences of ventricular conduction abnormalities after transcatheter aortic valve implantation. EuroIntervention 2014;9:1142-50.

13. Urena $M$, Mok $M$, Serra V, et al. Predictive factors and long-term clinical consequences of persistent left 
bundle branch block following transcatheter aortic valve implantation with a balloon-expandable valve. J Am Coll Cardiol 2012;60:1743-52.

14. Eriksson P, Hansson PO, Eriksson H, et al. Bundle-branch block in a general male population: the study of men born 1913. Circulation 1998;98:2494-500.

15. Prihadi EA, Leung M, Vollema EM, et al. Prevalence and prognostic relevance of ventricular conduction disturbances in patients with aortic stenosis. Am J Cardiol 2017;120:2226-32.

16. Siontis GC, Juni P, Pilgrim T, et al. Predictors of permanent pacemaker implantation in patients with severe aortic stenosis undergoing TAVR: a meta-analysis. J Am Coll Cardiol 2014;64:129-40.

17. Leon MB, Smith CR, Mack M, et al. Transcatheter aorticvalve implantation for aortic stenosis in patients who cannot undergo surgery. N Engl J Med 2010;363:1597-607.

18. Mack MJ, Leon MB, Thourani VH, et al. Transcatheter aortic-valve replacement with a balloon-expandable valve in low-risk patients. N Engl J Med 2019;380:1695-705.

19. Popma JJ, Deeb GM, Yakubov SJ, et al. Transcatheter aortic-valve replacement with a self-expanding valve in low-risk patients. N Engl J Med 2019;380:1706-15.

20. Dawkins S, Hobson AR, Kalra PR, et al. Permanent pacemaker implantation after isolated aortic valve replacement: incidence, indications, and predictors. Ann Thorac Surg 2008;85:108-12.

21. Khatri PJ, Webb JG, Rodés-Cabau J, et al. Adverse effects associated with transcatheter aortic valve implantation: a meta-analysis of contemporary studies. Ann Intern Med 2013;158:35-46.

22. Meduri CU, Kereiakes DJ, Rajagopal V, et al. Pacemaker implantation and dependency after transcatheter aortic valve replacement in the REPRISE III trial. J Am Heart Assoc 2019;8:e012594.

23. Van Mieghem NM, Wöhrle J, Hildick-Smith D, et al. Use of a repositionable and fully retrievable aortic valve in routine clinical practice: the RESPOND study and RESPOND extension cohort. JACC Cardiovasc Interv 2019;12:38-49.

24. Kodali S, Thourani VH, White J, et al. Early clinical and echocardiographic outcomes after SAPIEN 3 transcatheter aortic valve replacement in inoperable, high-risk and intermediate-risk patients with aortic stenosis. Eur Heart J 2016;37:2252-62.

25. Abramowitz Y, Jilaihawi H, Chakravarty T, et al. Sapien 3 transcatheter aortic valve implantation with moderate or without predilation. J Invasive Cardiol 2016;28:421-6.
26. Husser O, Pellegrini C, Kessler T, et al. Predictors of permanent pacemaker implantations and new-onset conduction abnormalities with the SAPIEN 3 balloonexpandable transcatheter heart valve. JACC Cardiovasc Interv 2016;9:244-54.

27. De Torres-Alba F, Kaleschke G, Diller GP, et al. Changes in the pacemaker rate after transition from edwards SAPIEN XT to SAPIEN 3 transcatheter aortic valve implantation: the critical role of valve implantation height. JACC Cardiovasc Interv 2016;9:805-13.

28. Wendler O, Schymik G, Treede H, et al. SOURCE 3 registry: design and 30-day results of the european postapproval registry of the latest generation of the SAPIEN 3 transcatheter heart valve. Circulation 2017;135:1123-32.

29. Gonska B, Seeger J, Keßler M, et al. Predictors for permanent pacemaker implantation in patients undergoing transfemoral aortic valve implantation with the Edwards Sapien 3 valve. Clin Res Cardiol 2017;106:590-7.

30. Finkelstein A, Steinvil A, Rozenbaum Z, et al. Efficacy and safety of new-generation transcatheter aortic valves: insights from the Israeli transcatheter aortic valve replacement registry. Clin Res Cardiol 2019;108:430-7.

31. Lanz J, Kim WK, Walther T, et al. Safety and efficacy of a self-expanding versus a balloon-expandable bioprosthesis for transcatheter aortic valve replacement in patients with symptomatic severe aortic stenosis: a randomised noninferiority trial. Lancet 2019;394:1619-28.

32. Nazif TM, Chen S, George I, et al. New-onset left bundle branch block after transcatheter aortic valve replacement is associated with adverse long-term clinical outcomes in intermediate-risk patients: an analysis from the PARTNER II trial. Eur Heart J 2019;40:2218-27.

33. Deharo P, Bisson A, Herbert J, et al. Impact of Sapien 3 balloon-expandable versus evolut $\mathrm{R}$ self-expandable transcatheter aortic valve implantation in patients with aortic stenosis: data from a nationwide analysis. Circulation 2020;141:260-8.

34. Nazif T, Daniels D, McCabe J, et al. editors. Real-world experience with the SAPIEN 3 Ultra TAVR: a propensity matched analysis from the United States. Transcatheter Valve Therapies; 2020.

35. Saia F, Gandolfo C, Palmerini T, et al. In-hospital and thirty-day outcomes of the SAPIEN 3 Ultra balloonexpandable transcatheter aortic valve: the S3U registry. EuroIntervention 2020;15:1240-7.

36. Popma JJ, Reardon MJ, Khabbaz K, et al. Early clinical outcomes after transcatheter aortic valve replacement 
using a novel self-expanding bioprosthesis in patients with severe aortic stenosis who are suboptimal for surgery: results of the Evolut R U.S. Study. JACC Cardiovasc Interv 2017;10:268-75.

37. Grube E, Van Mieghem NM, Bleiziffer S, et al. Clinical outcomes with a repositionable self-expanding transcatheter aortic valve prosthesis: the International FORWARD Study. J Am Coll Cardiol 2017;70:845-53.

38. Sorajja P, Kodali S, Reardon MJ, et al. Outcomes for the commercial use of self-expanding prostheses in transcatheter aortic valve replacement: a report from the STS/ACC TVT registry. JACC Cardiovasc Interv 2017;10:2090-8.

39. Reardon MJ, Van Mieghem NM, Popma JJ, et al. Surgical or transcatheter aortic-valve replacement in intermediaterisk patients. N Engl J Med 2017;376:1321-31.

40. Noble S, Stortecky S, Heg D, et al. Comparison of procedural and clinical outcomes with Evolut $\mathrm{R}$ versus Medtronic CoreValve: a Swiss TAVI registry analysis. EuroIntervention 2017;12:e2170-6.

41. Zaid S, Sengupta A, Okoli K, et al. Novel anatomic predictors of new persistent left bundle branch block after evolut transcatheter aortic valve implantation. Am J Cardiol 2020;125:1222-9.

42. Forrest JK, Kaple RK, Tang GHL, et al. Three generations of self-expanding transcatheter aortic valves: a report from the STS/ACC TVT registry. JACC Cardiovasc Interv 2020;13:170-9.

43. Jilaihawi H, Zhao Z, Du R, et al. Minimizing permanent pacemaker following repositionable self-expanding transcatheter aortic valve replacement. JACC Cardiovasc Interv 2019;12:1796-807.

44. Pagnesi M, Kim WK, Conradi L, et al. Transcatheter aortic valve replacement with next-generation selfexpanding devices: a multicenter, retrospective, propensitymatched comparison of evolut PRO versus acurate neo transcatheter heart valves. JACC Cardiovasc Interv 2019;12:433-43.

45. Hamm K, Reents $W$, Zacher $M$, et al. Transcatheter aortic valve implantation using the ACURATE TA and ACURATE neo valves: a four-year single-centre experience. EuroIntervention 2017;13:53-9.

46. Toggweiler S, Nissen H, Mogensen B, et al. Very low pacemaker rate following ACURATE neo transcatheter heart valve implantation. EuroIntervention 2017;13:1273-80.

47. Möllmann H, Hengstenberg C, Hilker M, et al. Realworld experience using the ACURATE neo prosthesis: 30- day outcomes of 1,000 patients enrolled in the SAVI TF registry. EuroIntervention 2018;13:e1764-70.

48. Brinkert M, Wolfrum M, Moccetti F, et al. Relevance of new conduction disorders after implantation of the ACURATE Neo Transcatheter Heart Valve in the Aortic Valve Position. Am J Cardiol 2020;125:783-7.

49. Manoharan G, Linke A, Moellmann H, et al. Multicentre clinical study evaluating a novel resheathable annular functioning self-expanding transcatheter aortic valve system: safety and performance results at 30 days with the Portico system. EuroIntervention 2016;12:768-74.

50. Möllmann H, Linke A, Holzhey DM, et al. Implantation and 30-day follow-up on all 4 valve sizes within the portico transcatheter aortic bioprosthetic family. JACC Cardiovasc Interv 2017;10:1538-47.

51. Linke A, Holzhey D, Möllmann H, et al. Treatment of aortic stenosis with a self-expanding, resheathable transcatheter valve: one-year results of the International Multicenter Portico Transcatheter Aortic Valve Implantation System Study. Circ Cardiovasc Interv 2018;11:e005206.

52. Søndergaard L, Rodés-Cabau J, Hans-Peter Linke A, et al. Transcatheter aortic valve replacement with a repositionable self-expanding prosthesis: the PORTICO-I trial 1-year outcomes. J Am Coll Cardiol 2018;72:2859-67.

53. Walther T, Manoharan G, Linke A, et al. Incidence of new-onset left bundle branch block and predictors of new permanent pacemaker following transcatheter aortic valve replacement with the Portico ${ }^{\mathrm{TM}}$ valve. Eur J Cardiothorac Surg 2018;54:467-74.

54. Fontana GP. Portico Re-sheathable Transcatheter Aortic Valve System US IDE Trial-PORTICO IDE. San Francisco: Transcatheter Cardiovascular Therapeutics; 2019.

55. Silaschi M, Treede H, Rastan AJ, et al. The JUPITER registry: 1-year results of transapical aortic valve implantation using a second-generation transcatheter heart valve in patients with aortic stenosis. Eur J Cardiothorac Surg 2016;50:874-81.

56. Wendler O, Schymik G, Treede H, et al. SOURCE 3: 1-year outcomes post-transcatheter aortic valve implantation using the latest generation of the balloonexpandable transcatheter heart valve. Eur Heart J 2017;38:2717-26.

57. Webb J, Gerosa G, Lefèvre T, et al. Multicenter evaluation of a next-generation balloon-expandable transcatheter aortic valve. J Am Coll Cardiol 2014;64:2235-43.

58. Mauri V, Reimann A, Stern D, et al. Predictors of 
permanent pacemaker implantation after transcatheter aortic valve replacement with the SAPIEN 3. JACC Cardiovasc Interv 2016;9:2200-9.

59. Schwerg M, Fulde F, Dreger H, et al. Optimized implantation height of the Edwards SAPIEN 3 valve to minimize pacemaker implantation after TAVI. J Interv Cardiol 2016;29:370-4.

60. Forrest JK, Mangi AA, Popma JJ, et al. Early outcomes with the evolut PRO repositionable self-expanding transcatheter aortic valve with pericardial wrap. JACC Cardiovasc Interv 2018;11:160-8.

61. Tang GHL, Zaid S, Michev I, et al. "Cusp-Overlap" view simplifies fluoroscopy-guided implantation of selfexpanding valve in transcatheter aortic valve replacement. JACC Cardiovasc Interv 2018;11:1663-5.

62. Götberg M, Bleiziffer S, Gooley R, et al. editor. Oneyear outcomes with the transcatheter LOTUS Edge aortic valve system. London: PCR London Valves; 2018.

63. Nazif TM, Dizon JM, Hahn RT, et al. Predictors and clinical outcomes of permanent pacemaker implantation after transcatheter aortic valve replacement: the PARTNER (Placement of AoRtic TraNscathetER Valves) trial and registry. JACC Cardiovasc Interv 2015;8:60-9.

64. Urena M, Webb JG, Tamburino C, et al. Permanent pacemaker implantation after transcatheter aortic valve implantation: impact on late clinical outcomes and left ventricular function. Circulation 2014;129:1233-43.

65. Buellesfeld L, Stortecky S, Heg D, et al. Impact of permanent pacemaker implantation on clinical outcome among patients undergoing transcatheter aortic valve implantation. J Am Coll Cardiol 2012;60:493-501.

66. Steinberg BA, Harrison JK, Frazier-Mills C, et al. Cardiac conduction system disease after transcatheter aortic valve replacement. Am Heart J 2012;164:664-71.

67. Erkapic D, De Rosa S, Kelava A, et al. Risk for permanent pacemaker after transcatheter aortic valve implantation: a comprehensive analysis of the literature. J Cardiovasc Electrophysiol 2012;23:391-7.

68. Nazif TM, Chen S, Kodali SK. Disarming the ticking time bomb: post-procedure electrocardiography predictors of high-degree conduction disturbances after transcatheter aortic valve replacement. JACC Cardiovasc Interv 2018;11:1527-30.

69. Rivard L, Schram G, Asgar A, et al. Electrocardiographic and electrophysiological predictors of atrioventricular block after transcatheter aortic valve replacement. Heart Rhythm 2015;12:321-9.

70. Watanabe Y, Kozuma K, Hioki H, et al. Pre-existing right bundle branch block increases risk for death after transcatheter aortic valve replacement with a balloonexpandable valve. JACC Cardiovasc Interv 2016;9:2210-6.

71. Auffret V, Webb JG, Eltchaninoff $H$, et al. Clinical impact of baseline right bundle branch block in patients undergoing transcatheter aortic valve replacement. JACC Cardiovasc Interv 2017;10:1564-74.

72. Petronio AS, Sinning JM, Van Mieghem N, et al. Optimal implantation depth and adherence to guidelines on permanent pacing to improve the results of transcatheter aortic valve replacement with the Medtronic CoreValve System: the CoreValve Prospective, International, PostMarket ADVANCE-II study. JACC Cardiovasc Interv 2015;8:837-46.

73. Auffret V, Puri R, Urena M, et al. Conduction disturbances after transcatheter aortic valve replacement: current status and future perspectives. Circulation 2017;136:1049-69.

74. Maeno Y, Abramowitz Y, Kawamori H, et al. A highly predictive risk model for pacemaker implantation after TAVR. JACC Cardiovasc Imaging 2017;10:1139-47.

75. Fujita B, Kütting M, Seiffert M, et al. Calcium distribution patterns of the aortic valve as a risk factor for the need of permanent pacemaker implantation after transcatheter aortic valve implantation. Eur Heart J Cardiovasc Imaging 2016;17:1385-93.

76. Sweeney MO, Hellkamp AS. Heart failure during cardiac pacing. Circulation 2006;113:2082-8.

77. Nielsen JC, Kristensen L, Andersen HR, et al. A randomized comparison of atrial and dual-chamber pacing in 177 consecutive patients with sick sinus syndrome: echocardiographic and clinical outcome. J Am Coll Cardiol 2003;42:614-23.

78. Sweeney MO, Hellkamp AS, Ellenbogen KA, et al. Adverse effect of ventricular pacing on heart failure and atrial fibrillation among patients with normal baseline QRS duration in a clinical trial of pacemaker therapy for sinus node dysfunction. Circulation 2003;107:2932-7.

79. Wilkoff BL, Cook JR, Epstein AE, et al. Dual-chamber pacing or ventricular backup pacing in patients with an implantable defibrillator: the Dual Chamber and VVI Implantable Defibrillator (DAVID) Trial. JAMA 2002;288:3115-23.

80. Dizon JM, Nazif TM, Hess PL, et al. Chronic pacing and adverse outcomes after transcatheter aortic valve implantation. Heart 2015;101:1665-71.

81. Faroux L, Chen S, Muntane-Carol G, et al. Clinical impact of conduction disturbances in transcatheter aortic valve replacement recipients: a systematic review and 
meta-analysis. Eur Heart J 2020;41:2771-81.

82. Hoffmann R, Herpertz R, Lotfipour S, et al. Impact of a new conduction defect after transcatheter aortic valve implantation on left ventricular function. JACC Cardiovasc Interv 2012;5:1257-63.

83. Chevreul K, Brunn M, Cadier B, et al. Cost of transcatheter aortic valve implantation and factors associated with higher hospital stay cost in patients of the FRANCE (FRench Aortic National CoreValve and Edwards) registry. Arch Cardiovasc Dis 2013;106:209-19.

84. Gutmann A, Kaier K, Sorg S, et al. Analysis of the additional costs of clinical complications in patients undergoing transcatheter aortic valve replacement in the German Health Care System. Int J Cardiol 2015;179:231-7.

85. Poels TT, Houthuizen P, Van Garsse LA, et al. Frequency and prognosis of new bundle branch block induced by surgical aortic valve replacement. Eur J Cardiothorac Surg 2015;47:e47-53.

86. Panchal HB, Barry N, Bhatheja S, et al. Mortality and major adverse cardiovascular events after transcatheter aortic valve replacement using Edwards valve versus CoreValve: a meta-analysis. Cardiovasc Revasc Med 2016;17:24-33.

87. Muntané-Carol G, Guimaraes L, Ferreira-Neto AN, et al. How does new-onset left bundle branch block affect the outcomes of transcatheter aortic valve repair? Expert Rev Med Devices 2019;16:589-602.

88. Rampat R, Khawaja MZ, Hilling-Smith R, et al. Conduction abnormalities and permanent pacemaker implantation after transcatheter aortic valve replacement using the Repositionable LOTUS Device: the United Kingdom experience. JACC Cardiovasc Interv 2017;10:1247-53.

89. Massoullié G, Bordachar P, Ellenbogen KA, et al. Newonset left bundle branch block induced by transcutaneous aortic valve implantation. Am J Cardiol 2016;117:867-73.

90. Jochheim D, Zadrozny M, Theiss H, et al. Aortic regurgitation with second versus third-generation balloon-expandable prostheses in patients undergoing transcatheter aortic valve implantation. EuroIntervention 2015;11:214-20.

91. Testa L, Latib A, De Marco F, et al. Clinical impact of persistent left bundle-branch block after transcatheter aortic valve implantation with CoreValve Revalving System. Circulation 2013;127:1300-7.

92. Nazif TM, Williams MR, Hahn RT, et al. Clinical implications of new-onset left bundle branch block after transcatheter aortic valve replacement: analysis of the PARTNER experience. Eur Heart J 2014;35:1599-607.

93. Rodés-Cabau J, Urena M, Nombela-Franco L, et al. Arrhythmic burden as determined by ambulatory continuous cardiac monitoring in patients with new-onset persistent left bundle branch block following transcatheter aortic valve replacement: the MARE study. JACC Cardiovasc Interv. 2018;11:1495-505.

94. Piazza N, Nuis RJ, Tzikas A, et al. Persistent conduction abnormalities and requirements for pacemaking six months after transcatheter aortic valve implantation. EuroIntervention 2010;6:475-84.

95. Piazza N, Onuma Y, Jesserun E, et al. Early and persistent intraventricular conduction abnormalities and requirements for pacemaking after percutaneous replacement of the aortic valve. JACC Cardiovasc Interv 2008;1:310-6.

96. Schymik G, Tzamalis P, Bramlage P, et al. Clinical impact of a new left bundle branch block following TAVI implantation: 1-year results of the TAVIK cohort. Clin Res Cardiol 2015;104:351-62.

97. Houthuizen P, Van Garsse LA, Poels TT, et al. Left bundle-branch block induced by transcatheter aortic valve implantation increases risk of death. Circulation 2012;126:720-8.

98. Oestreich BA, Mbai M, Gurevich S, et al. Computed tomography (CT) assessment of the membranous septal anatomy prior to transcatheter aortic valve replacement (TAVR) with the balloon-expandable SAPIEN 3 valve. Cardiovasc Revasc Med 2018;19:626-31.

99. Carrabba N, Valenti R, Migliorini A, et al. Impact on left ventricular function and remodeling and on 1-year outcome in patients with left bundle branch block after transcatheter aortic valve implantation. Am J Cardiol 2015;116:125-31.

100. Urena M, Webb JG, Cheema A, et al. Impact of newonset persistent left bundle branch block on late clinical outcomes in patients undergoing transcatheter aortic valve implantation with a balloon-expandable valve. JACC Cardiovasc Interv 2014;7:128-36.

101. Regueiro A, Abdul-Jawad Altisent O, Del Trigo M, et al. Impact of new-onset left bundle branch block and periprocedural permanent pacemaker implantation on clinical outcomes in patients undergoing transcatheter aortic valve replacement: a systematic review and metaanalysis. Circ Cardiovasc Interv 2016;9:e003635.

102. Kutyifa V, Pouleur AC, Knappe D, et al. Dyssynchrony and the risk of ventricular arrhythmias. JACC Cardiovasc 
Imaging 2013;6:432-44.

103.Xiao HB, Lee CH, Gibson DG. Effect of left bundle branch block on diastolic function in dilated cardiomyopathy. Br Heart J 1991;66:443-7.

104.Priesler O, Biner S, Finkelstein A, et al. Conduction abnormalities after transcatheter aortic valve implantation and diastolic dysfunction. Cardiology 2017;137:36-42.

105. Cerrato E, Nombela-Franco L, Nazif TM, et al. Evaluation of current practices in transcatheter aortic valve implantation: The WRITTEN (WoRldwIde TAVI

Cite this article as: Chen S, Chau KH, Nazif TM. The incidence and impact of cardiac conduction disturbances after transcatheter aortic valve replacement. Ann Cardiothorac Surg 2020;9(6):452-467. doi: 10.21037/acs-2020-av-23
ExperieNce) survey. Int J Cardiol 2017;228:640-7.

106. Naveh S, Perlman GY, Elitsur Y, et al.

Electrocardiographic predictors of long-term cardiac pacing dependency following transcatheter aortic valve implantation. J Cardiovasc Electrophysiol 2017;28:216-23. 107. Rodés-Cabau J, Ellenbogen KA, Krahn AD, et al. Management of conduction disturbances associated with transcatheter aortic valve replacement: JACC Scientific Expert Panel. J Am Coll Cardiol 2019;74:1086-106. 